\title{
A Study on the Safe Hydrogen Exhaust Method in the Semiconductor Industry
}

\author{
Seongmin $\mathrm{Seo}^{1}$, Yong-Won Song ${ }^{2}$ \\ ${ }^{I}$ Technical Master, Future Technology R\&D, SKHynix Semiconductor, Korea, \\ miniseo0101@naver.com \\ ${ }^{2}$ Professor, Dept. Nano \& Semiconductor Engineering, Polytechnic University, Korea, \\ ywsong@kpu.ac.kr \\ Corresponding author: Seongmin Seo
}

\begin{abstract}
This study proposed a solution to prevent explosion accidents that may occur in the process of exhausting hydrogen in the semiconductor industry. Furthermore, it developed a hydrogen plasma treatment unit (HPTU) that converts exhausted hydrogen gas into safe water vapor using functionoriented search (FOS), which is one of the TRIZ tools. Also, the core technology of the renewable energy industry was applided to convert a greenhouse gas into clean energy using a plasma carbon conversion unit (PCCU). The correlation between the decomposition rate and each factor was found through the experiment of plasma decomposition and chemical reaction by mixing oxygen with exhausted hydrogen. The decomposition rate is higher as the amount of hydrogen decreases or both oxygen and RF power increases. Based on the experiment, the optimal combination of degradation rates was determined. With $9.17 \mathrm{slm}$ of hydrogen, $20 \mathrm{slm}$ of oxygen and $4.93 \mathrm{~kW}$ of RF power, the decomposition rate is $100 \%$. Data was collected through the design of experimental using the split-plot design, and the data was optimized using the JMP statistical program provided by SAS. A hydrogen exhaust safety system was constructed by combining HPTU ans hydrogen dilution unit (NDU), ang the system operation experiment was conducted. Using 40slm of hydrogen, which is 4 times that of the existing system, the result was obtained that the concentration in the non-explosive range could bo controlled. The construction of hydrogen exhaust safety system suggested a new method to prevent serious industrial accidents by using a large amount of hydrogen used in semiconductor process development and then discharging it in a safe state.
\end{abstract}

Keywords: Hydrogen Exhaust Safety System, Hydrogen Plasma Treatment Unit, TRIZ, FunctionOriented Search, Split-plot

\section{Introduction}

In recent years, the use of hydrogen is increasing in the semiconductor industry to remove impurities and improve properties. In addition, hydrogen has higher combustion heat than petroleum and more than $10 \%$ higher thermal efficiency than thermal power plants. Thus, hydrogen is increasingly being used throughout the industry as an eco-friendly energy source that does not emit carbon, which is an environmental pollutant. However, hydrogen is a highly flammable gas that burns quickly, and has the property of a strong explosion when it comes into contact with an ignition source such as heat or sparks.

In 2010, a Soso cartridge exploded during a hydrogen transfer operation at a hydrochloric acid

Received: January 17, 2021; $1^{\text {st }}$ Review Result: March 02, 2021; $2^{\text {nd }}$ Review Result: April 20, 2021

Accepted: May 25, 2021 
production plant in Gunsan, Jeollabuk-do, killing one worker and injuring one. The container was scattered up to 200 meters by the explosive force, and the explosive cartridge was moved to the rear 3 meters by the explosion reaction[1].

On May 23, 2019, a hydrogen explosion accident occurred at Gangwon Techno Park, which was developing power-independent fuel cell-solar wind hybrid power generation technology, two people died and six people were injured. It was an accident that exploded due to static electricity in a state where more than the allowable amount of oxygen was mixed in the hydrogen storage tank and buffer tank manufactured in the water electrolysis facility.

Hydrogen-related accidents are serious industrial accidents that cause most of the casulaties. If hydrogen leaks during transport or usage, a flame is generated when a combustible gas mixture becomes an ignition source. The outcome of high temperature and high pressure is considerably destructive[2]. To prevent such incidents, hydrogen gas must be discharged in a safe state after use. If hydrogen gas leaks within the explosive range, it absorbs the surrounding oxygen and spreads the fire and explosion rapidly, and serious environmental destruction will occur. Research on the scope of the hydrogen explosion is ongoing. However, no research has been conducted to prevent explosion accidents caused by hydrogen exhausted after use. Therefore, this study included the development of a device capable of converting hydrogen to a safe state, which is used to improve the characteristics of the semiconductor industry, and the construction of an exhaust system.

\section{Literature Review}

\subsection{Hydrogen Explosion}

According to the material safety data reported by the Korea Safety and Health Agency, the ignition point of hydrogen is about 500 degrees celsius and the explosion range of hydrogen is 4 to $75 \%$, which is 8 to 10 times wider than that of methane and propane, and its auto ignition temperature is about 40 degrees celsius lower, so it is more exposed to the risk of explosion. The explosion pressure is 8 atms, which is more than 10 times, and the combustion speed is $2.7 \mathrm{~m} / \mathrm{s}$, which is 8 times faster that of methane and propane. The gas properties of hydrogen are far more dangerous than gases used as domestic fuels, as listed in [Table 1][3][4]. Material information ar 1 atm and 0 degrees Celsius.

[Table 1] Characteristics of Fuel Gas

\begin{tabular}{|c|c|c|c|c|c|}
\hline Substance & $\begin{array}{c}\text { Lower } \\
\text { explosion limit } \\
(\%)\end{array}$ & $\begin{array}{c}\text { Upper explosion } \\
\text { limit }(\%)\end{array}$ & $\begin{array}{c}\text { Auto ignition } \\
\text { temperature } \\
\left({ }^{\circ} \mathrm{C}\right)\end{array}$ & $\begin{array}{c}\text { Minimum } \\
\text { ignition energy }(\mathrm{mJ})\end{array}$ & $\begin{array}{c}\text { Combustion } \\
\text { speed } \\
(\mathrm{m} / \mathrm{s})\end{array}$ \\
\hline Hydrogen & 4 & 75 & 399.85 & 0.018 & 2.7 \\
\hline Methane & 5 & 15 & 439.85 & 0.28 & 0.37 \\
\hline Propane & 2.1 & 9.5 & 449.85 & 0.26 & 0.39 \\
\hline
\end{tabular}

As shown in [Table 2], as a result of experimenting with the hydrogen explosion range while increasing the temperature from room temperature to 400 degrees Celsius based on 1 atm, the hydrogen explosion range expands as the temperature rises[5].

If hydrogen and air are mixed at the same ratio and the pressure is increased from 1 atm to $150 \mathrm{~atm}$, the explosion range of hydrogen increases from 4.3 to $76.5 \%$ to 5.6 to $72.9 \%$, with the lower limit increasing by $1.3 \%$ and the upper limit by $3.6 \%$ lowering, resulting in atal range of $4.9 \%$ decrease.

If oxygen is mixed instead of air in the same way, the explosion range of hydrogen is increased by $1.7 \%$ from 4.0 to $95.2 \%$ to 5.7 to $95.1 \%$, and the upper limit is increased by $1.7 \%$ and the upper limit 
is decreased by $0.1 \%$, so that the entire range is reduced by $1.8 \%$.

[Table 2] Hydrogen Explosion Characteristics according to Increasing Temperature

\begin{tabular}{|c|c|c|}
\hline Temperature $\left({ }^{\circ} \mathrm{C}\right)$ & Lower explosion limit $(\%)$ & Upper explosion limit (\%) \\
\hline 20 & 3.9 & 75.2 \\
\hline 100 & 3.4 & 77.6 \\
\hline 200 & 2.9 & 81.3 \\
\hline 300 & 2.1 & 83.9 \\
\hline 400 & 1.5 & 87.6 \\
\hline
\end{tabular}

Therefore, it can be seen that the increase in pressure slightly decreases the explosion range, and when the mixture is oxygen, the total explosion range increases by $20 \%[6]$.

The result of the explosion experiment in vacuum after hydrogen and air are mixed, the lower explosion limit at $10 \%$ hydrogen concentration is 0.4 atm and the lower explosion limit at $60 \%$ hydrogen concentration is $0.6 \mathrm{~atm}$. At $30 \%$ hydrogen concentration, the lower explosion limit is lowest at $0.2 \mathrm{~atm}$. That is below $0.2 \mathrm{~atm}$, there is no explosion point regardless of the hydrogen concentration [7][Fig. 1].

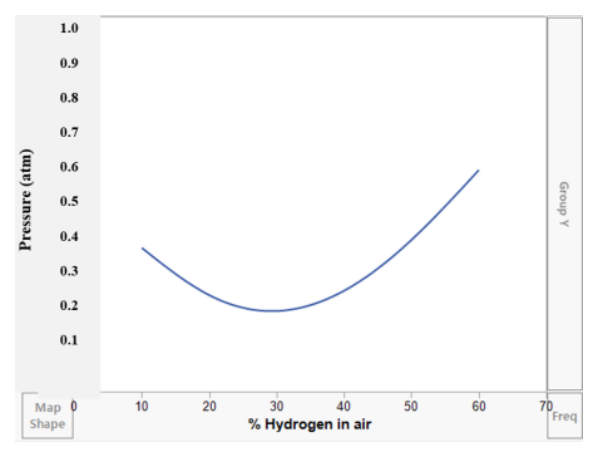

[Fig. 1] Explosion Range Under Vacuum

Although hydrogen has strong explosive power, it can be seen that it does not overpressure be exploding even at the flash point below $0.2 \mathrm{~atm}$. Therefore, the hydrogen converion or removal unit must be constructed in vacuum below $0.2 \mathrm{~atm}$.

\subsection{TRIZ}

TRIZ is Theory of Inventive Problem Solving compiled by Genrich Altshuller and his colleagues , and has developed a number of tools and techniques to advance TRIZ[8]. Representatively, it includes 9 windows and multi-screens, system resource analysis, functional analysis, material field analysis, ideal end result, 76 standard solutions, contradiction matrices, 40 invention principles, separation principles, the laws of evolution of technological systems[9]. This new forecasting method based on evolutionary patterns is intended to help in predicting future technologies objectively, as opposed to the subjective views of analysts[10]. As an example, there is a study that predicts that the future TV will use the micro LED display that is in the growth stage after its birth period through S-curve analysis[11].

A new TRIZ-based tool, the function-oriented search, is a knowledge-search technique developed by 
function analysis technique of TRIZ. The order of execution of FOS is to define systems and problems based on functions, generalize functions, and then searche for a system that performs the same function in the world scientific database centered on leading industries or high-tech industries. Then, apply the best solution applicable to the current system among other industry solutions. The solution is a proven and effective method and should be reliable to eliminate uncertainty.

\section{Development of Hydrogen Plasma Treatment Unit}

\subsection{Hydrogen Plasma Treatment Unit}

Nitrogen dilution methods have limitations in order to use and safely discharge the increased hydrogen. According to explosion-proof standards, the concentration of exhausted hydrogen must be $1 \%$ or less, and the gas removal device can treat up to $1000 \mathrm{slm}$ per minute, so it is possible to physically use $10 \mathrm{slm}$ per minute. Process development requires more than $10 \mathrm{slm}$ of hydrogen, so it is necessary to develop a new hydrogen exhaust safety system.

[Fig. 2] shows a current exhaust system that physically controls the concentration of hydrogen exhausted using the nitrogen dilution unit.

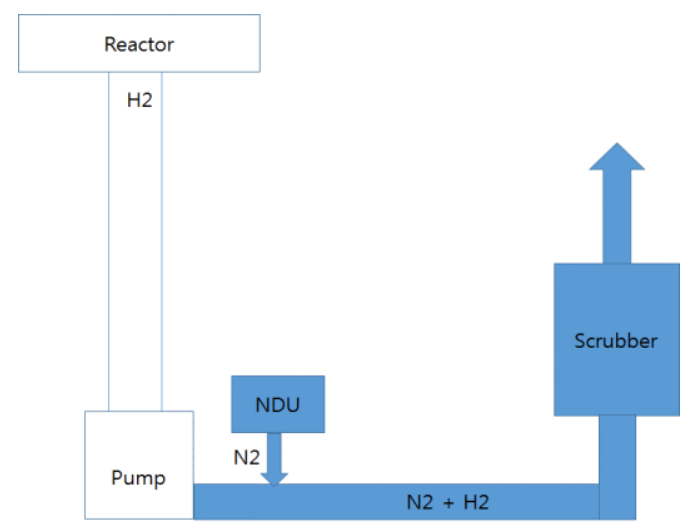

[Fig. 2] Current Hydrogen Exhaust System

For the development of new devices, TRIZ's function-oriented search was used.

The FOS method proceeds by defining the problem, generalizing the function or problem, deriving an existing methodology, and applying it to the current system.

The physical limitation of the current hydrogen exhaust system is the treatment of $10 \mathrm{slm}$ of hydrogen consumption by the method of nitrogen dilution. In the development of a new process, the problem was defined as the limit of not being able to use hydrogen of 10slm or more, and the point that the hydrogen consumption that satisfies the development conditions can be safely handled was approached as the main function.

A generalized problem is the presence of large amounts of hamful dangerous gases. Hazardous gases are released from the system.

Keywords searched for generalization of the problem are harmful gases, greenhouse gases, exhaust gases, decomposition, safe substances, conversion, substitution. The existing solution searched in this way was a clean energy production plant in the renewable energy industry.

The greenhouse gases carbon dioxide and methane are mixed, and hydrogen abd carbon monoxide are produced through decomposition and chemical reactions in a plasma carbon conversion unit (PCCU). This gas is used to produce dimethyl ether (DME), a clean fuel[12]. The process diagram of the DME production plant and the structure of the PCCU are organized as shown in [Fig. 3]. 

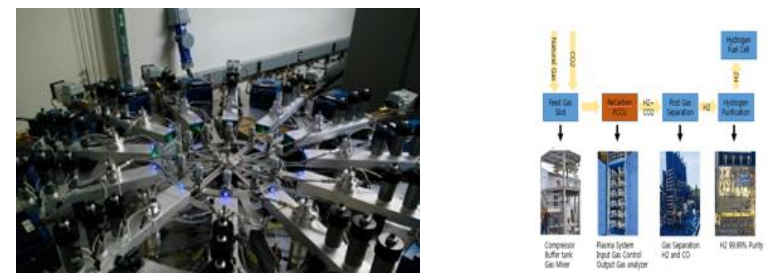

[Fig. 3] Plasma Carbon Conversion Unit (PCCU) and Pilot plant by ReCarbon

A plasma unit capable of inducing a chemical reaction and decomposition of hydrogen and oxygen in the present hydrogen exhaust system was applied as shown in [Fig. 4]. The type of plasma unit is a transformer coupled plasma capable of applying a radio frequency (RF) of $400 \mathrm{kHz}$ and power of $6 \mathrm{~kW}$. This device is called a small plasma treatment device. A hydrogen sensor was installed behind the pump to measure the hydrogen concentration of hydrogen contained in the exhaust gas[13].
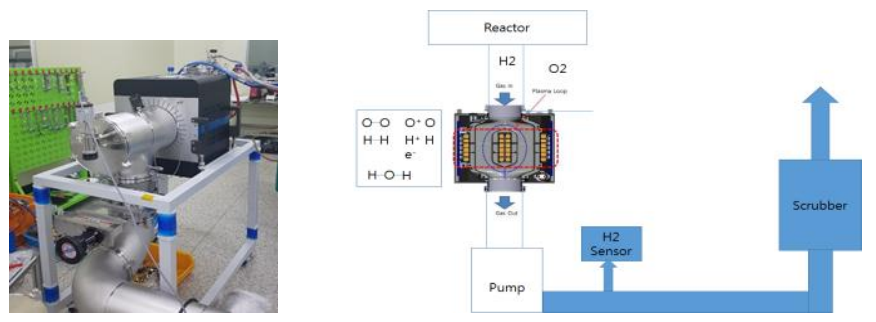

[Fig. 4] Hydrogen Plasma Treatment Unit

\subsection{Method of Experiment}

This experiment was conducted to confirm whether hydrogen conversion feasibility experiment can be converted into a safe material in a plasma device by mixing oxygen that induces a chemical reaction with the exhausted hydrogen and applying RF power for decomposition, and to confirm the correlation between each factor and the decomposition rate. The independent variable selects only one of hydrogen, oxygen, RF power, the other two factors that cannot be selected become the control variable, and the dependent variable becomes the decomposition rte. To verify the correlation of each factor, a total of 3 experiments are performed for each independent variable.

The experimental table is processed by split-plot design, and data analysis and optimization are performed through polynomial multiple regression analysis provided by SAS' JMP statistical software. Because it performs complex reactions in the reaction tube, it is necessary to apply polynomials, and we used JMP, which allows powerful analysis even if you are not a statistical expert.

\subsection{Feasibility Experiment}

Experiments were conducted with a split-plot design method using factors of hydrogen, oxygen, RF power. To verify the decomposition rates according to the amount of hydrogen, the amount of oxygen was $12 \mathrm{slm}$, RF power was $6.0 \mathrm{~kW}$ fixed, and the amount of hydrogen was increased from $2.5 \mathrm{slm}$ to $20.5 \mathrm{slm}$ in $2 \mathrm{slm}$ increments; the decomposition rate at $2.5 \mathrm{slm}$ of hydrogen was $99.1 \%$, and at $20.5 \mathrm{slm}$ of hydrogen was $65.2 \%$. The results of each experiment are detailed in [Table 3].

As the amount of hydrogen increases, the decomposition rate decreases, which is inversely proportional to each other[13]. [Table 3] lists the detailed experimental results.

To verify the decomposition rates according to the amount of oxygen, the amount of hydrogen was $10 \mathrm{slm}$, RF power was $6.0 \mathrm{~kW}$ fixed, and the amount of oxygen was increased from $2.5 \mathrm{~s} 1 \mathrm{~m}$ to $20 \mathrm{slm}$ in $2.5 \mathrm{~s} / \mathrm{m}$ increments. At this time, the ratio of hydrogen and oxygen is from $25 \%$ to $200 \%$; the 
decomposition rate at $2.5 \mathrm{~s} / \mathrm{m}$ of oxygen was $38.7 \%$, and at $20 \mathrm{slm}$ of oxygen was $92.8 \%$. The results of each experiment are detailed in [Table 4].

[Table 3] Decomposition Rate according to the Amount of Hydrogen

\begin{tabular}{|c|c|c|c|c|c|c|}
\hline No. & $\begin{array}{c}\mathrm{H} 2 \\
(\mathrm{slm})\end{array}$ & $\begin{array}{c}\text { O2 } \\
(\mathrm{slm})\end{array}$ & $\begin{array}{c}\text { RF Power } \\
(\mathrm{kW})\end{array}$ & $\begin{array}{c}\text { Before } \\
\text { Concentration (\%) }\end{array}$ & $\begin{array}{c}\text { After } \\
\text { Concentration (\%) }\end{array}$ & $\begin{array}{c}\text { Decomposition } \\
\text { Rate }\end{array}$ \\
\hline 1 & 2.5 & 12.0 & 6.0 & 1.36 & 0.01 & $99.1 \%$ \\
2 & 4.5 & 12.0 & 6.0 & 2.41 & 0.40 & $83.4 \%$ \\
\hline 3 & 6.5 & 12.0 & 6.0 & 3.45 & 1.04 & $79.1 \%$ \\
\hline 4 & 8.5 & 12.0 & 6.0 & 4.46 & 1.40 & $76.7 \%$ \\
5 & 10.5 & 12.0 & 6.0 & 5.45 & 1.72 & $73.2 \%$ \\
\hline 6 & 12.5 & 12.0 & 6.0 & 6.43 & 2.20 & $70.2 \%$ \\
\hline 7 & 14.5 & 12.0 & 6.0 & 7.38 & 2.68 & $67.8 \%$ \\
\hline 8 & 16.5 & 12.0 & 6.0 & 8.31 & 3.04 & $67.1 \%$ \\
\hline 9 & 18.5 & 12.0 & 6.0 & 9.23 & 3.52 & $65.2 \%$ \\
\hline 10 & 20.5 & 12.0 & 6.0 & 10.00 & & $73 \%$ \\
\hline
\end{tabular}

[Table 4] Decomposition Rates according to the Amount of Oxygen (Ratio of Hydrogen-oxygen)

\begin{tabular}{|c|c|c|c|c|c|c|c|}
\hline No & $\begin{array}{c}\mathrm{H} 2 \\
(\mathrm{slm})\end{array}$ & $\begin{array}{c}\mathrm{O} 2 \\
(\mathrm{slm})\end{array}$ & $\begin{array}{c}\text { Ratio of H2 } \\
\text { to O2 }(\%)\end{array}$ & $\begin{array}{c}\text { RF power } \\
(\mathrm{kW})\end{array}$ & $\begin{array}{c}\text { Before con- } \\
\text { centration (\%) }\end{array}$ & $\begin{array}{c}\text { After con- } \\
\text { centration (\%) }\end{array}$ & $\begin{array}{c}\text { Decompo- sition } \\
\text { rate }\end{array}$ \\
\hline 1 & 10.0 & 2.5 & 25.0 & 6.0 & 5.48 & 3.36 & $38.7 \%$ \\
\hline 2 & 10.0 & 5.0 & 50.0 & 6.0 & 5.41 & 2.76 & $48.9 \%$ \\
\hline 3 & 10.0 & 7.5 & 75.0 & 6.0 & 5.33 & 2.16 & $59.5 \%$ \\
\hline 4 & 10.0 & 10.0 & 100.0 & 6.0 & 5.26 & 1.52 & $71.1 \%$ \\
\hline 5 & 10.0 & 12.5 & 125.0 & 6.0 & 5.19 & 1.00 & $80.8 \%$ \\
\hline 6 & 10.0 & 15.0 & 150.0 & 6.0 & 5.13 & 0.68 & $86.7 \%$ \\
\hline 7 & 10.0 & 17.5 & 175.0 & 6.0 & 5.06 & 0.48 & $90.5 \%$ \\
\hline 8 & 10.0 & 20.0 & 200.0 & 6.0 & 5.00 & 0.36 & $92.8 \%$ \\
\hline
\end{tabular}

As the amount of oxygen increases, the decomposition rate increases[13]. [Table 4] lists the detailed experimental results.

To verify the decomposition rates according to RF power, the amount of hydrogen was 10slm, the amount of oxygen was $15 \mathrm{slm}$ fixed, and RF power was increased from $1.5 \mathrm{~kW}$ to $6 \mathrm{~kW}$ in $0.5 \mathrm{~kW}$ increments; the decomposition rate at $1.5 \mathrm{~kW}$ of RF power was $43.1 \%$, and at $6.0 \mathrm{~kW}$ of RF power was 87.5\%. The results of each experiment are detailed in [Table 5].

As the RF power increases, the decomposition rate increases and the decomposition rate saturates above 5.0kW[13]. [Table 5] lists the detailed experimental results.

The optimal combination of decomposition rates was determined through the results of the three experiments presented based on the split-plot design and multiple regression analysis of polynomials[Fig. 5]. When using $9.17 \mathrm{slm}$ of hydrogen, $20 \mathrm{slm}$ of oxygen, and $4.93 \mathrm{~kW}$ of RF power, the decomposition rate is $100 \%$, and desirability is $98.2 \%$.. The optimal combination of decomposition rates at the maximum amount of hydrogen was also confirmed[Fig. 6]. When using $20 \mathrm{slm}$ of hydrogen, $20 \mathrm{slm}$ of oxygen, and $4.93 \mathrm{~kW}$ of RF power, the decomposition rate is $88.6 \%$, and desirability is $82.3 \%$. 
[Table 5] Decomposition Rates according to RF Power

\begin{tabular}{|c|c|c|c|c|c|c|}
\hline No. & $\begin{array}{c}\mathrm{H} 2 \\
(\mathrm{~s} \operatorname{lm})\end{array}$ & $\begin{array}{c}\text { O2 } \\
(\mathrm{s} \operatorname{m})\end{array}$ & $\begin{array}{c}\text { RF Power } \\
(\mathrm{kW})\end{array}$ & $\begin{array}{c}\text { Before Concent- } \\
\text { ration }(\%)\end{array}$ & $\begin{array}{c}\text { After Concent- } \\
\text { ration }(\%)\end{array}$ & $\begin{array}{c}\text { Decomposition } \\
\text { Rate }\end{array}$ \\
\hline 1 & 10.0 & 15.0 & 1.5 & 5.13 & 2.92 & $43.1 \%$ \\
\hline 2 & 10.0 & 15.0 & 2.0 & 5.13 & 2.24 & $56.3 \%$ \\
\hline 3 & 10.0 & 15.0 & 2.5 & 5.13 & 1.64 & $68.0 \%$ \\
\hline 4 & 10.0 & 15.0 & 3.0 & 5.13 & 0.96 & $86.6 \%$ \\
\hline 5 & 10.0 & 15.0 & 3.5 & 5.13 & 0.76 & $85.2 \%$ \\
\hline 6 & 10.0 & 15.0 & 4.0 & 5.13 & 0.72 & $86.0 \%$ \\
\hline 7 & 10.0 & 15.0 & 4.5 & 5.13 & 0.64 & $87.5 \%$ \\
\hline 8 & 10.0 & 15.0 & 5.0 & 5.13 & 0.64 & $87.5 \%$ \\
\hline 9 & 10.0 & 15.0 & 5.5 & 5.13 & 0.64 & $87.5 \%$ \\
\hline 10 & 10.0 & 15.0 & 6.0 & 5.13 & & \\
\hline
\end{tabular}

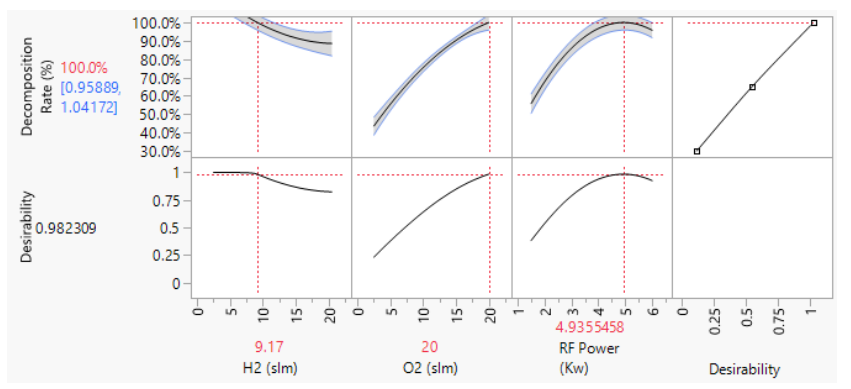

[Fig. 5] Optimal Combination for the Maximum Decomposition Rate

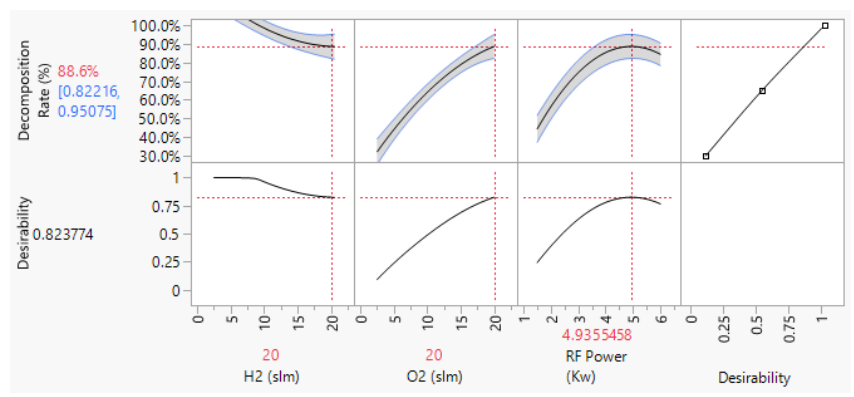

[Fig. 6] Optimal Decomposition Rate Combination at Maximum Amouny of Hydrogen

In order to avoid the risk of exhausted hydrogen, a hydrogen plasma treatment unit was developed by applying the core technology that has already been verified in the renewable energy industry, and applicability was confirmed through experiments. The concept of the decision to develop a hydrogen plasma treatment unit could be completed in the range of minimizing trial and error with FOS.

\section{Construction of Hydrogen Exhaust Safety System}

In order to use and safely exhaust the large amount of hydrogen required for process development, HPTU and NDU have been combined to construction a hydrogen exhaust safety system. This system is constructed to convert hydrogen to a safe state and to control the concentration of residual hydrogen exhausted to $1 \%$ below the lower explosion limit. HPTU converts the exhausted hydrogen into primary and dilutes with the amount of nitrogen, as shown in [Fig. 7]. 


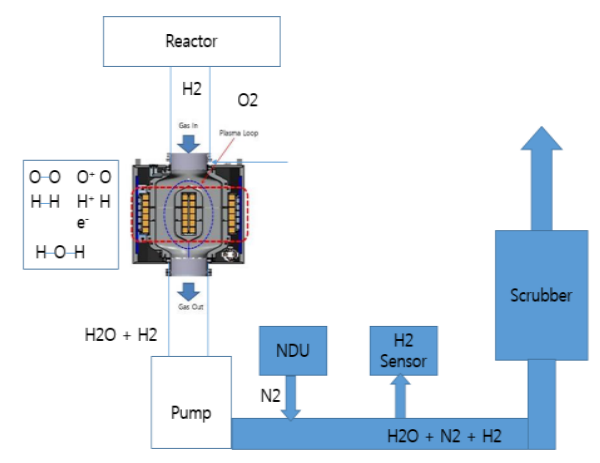

[Fig. 7] Hydrogen Exhaust Safety System

The flow rate of the NDU is fixed with a manual flow meter and, if necessary, is diluted by opening the valve. The flow rate is 100 times the maximum amount of hydrogen available, or meets the allowable limits of the gas scrubber. The maximum capacity is used as a way to ensure safety, but the gas scrubber is overloaded. Hence, a physical contradiction occurs.

\subsection{Physical Contradiction}

Physical contradiction 1: In order to ensure the safety of hydrogen exhausted after the primary decomposition in HPTU, it is necessary to add a large amount of diluted nitrogen in the NDU.

Physical contradiction $2:$ In order to reduce the load of the gas scrubber, a small amount of nitrogen must be addes in the NDU.

In order to ensure the safety of the hydrogen exhausted after the primary decomposition in HPTU and reduce the load of the gas scrubber, it is necessary to add a large amount or small amount of diluted nitrogen in the NDU.

The conditional separation (partial and full) technique was applied to resolve the physical contradiction. If the exhaust hydrogen concentration is high after the promary decomposition with the HPTU, add a large amount of diluted nitrogen to lower the hydrogen concentration, and if the exhaust hydrogen concentration is low, add a small amount of diluted nitrogen to reduce the load of the gas scrubber. Therfore, the NDU has been improved by changing it to a variable type that can be automatically controlled according to the hydrogen concentration[14].

\subsection{Split-plot Experiment}

The experiment in the hydrogen exhaust safety system was conducted by applying the feasibility experiment in Chapter 3 and the principle of solving physical contradictions. Experiments were conducted with various structures that can be applied, and hydrogen and oxygen fluctuate according to the process conditions, and the maximum value of RF power with good efficiency was applied. The experiment was conducted by calculating the diluted nitrogen of NDU according to the concentration exhausted after the first decomposition in HPTU. The results of each experiment are detailed in [Table $6]$.

[Table 6] split-plot Experiment of Hydrogen Exhaust Safety System

\begin{tabular}{|c|c|c|c|c|c|c|c|c|c|}
\hline $\begin{array}{c}\mathrm{H} 2 \\
(\mathrm{slm})\end{array}$ & $\begin{array}{c}\mathrm{O} 2 \\
(\mathrm{slm})\end{array}$ & $\begin{array}{c}\text { Ratio } \\
(\mathrm{H} 2: \mathrm{O} 2)\end{array}$ & $\begin{array}{c}\text { Pump } \\
\text { N2 }(\mathrm{slm})\end{array}$ & $\begin{array}{c}\text { PPS Size } \\
(\mathrm{mm})\end{array}$ & $\begin{array}{c}\text { RF Power } \\
(\mathrm{kW})\end{array}$ & $\begin{array}{c}\text { Before } \\
\mathrm{H} 2 \%\end{array}$ & $\begin{array}{c}\text { After } \\
\mathrm{H} 2 \%\end{array}$ & $\begin{array}{c}\text { NDU } \\
(\mathrm{Slm})\end{array}$ & Exhaust \% \\
\hline 30 & 21 & 0.7 & 130 & 250 & 6.0 & 16.57 & 5.08 & 780 & 0.87 \\
\hline 35 & 24.5 & 0.7 & 130 & 250 & 6.0 & 18.47 & 5.44 & 875 & 0.88 \\
\hline 40 & 28 & 0.7 & 130 & 250 & 6.0 & 20.20 & 6.73 & 995 & 0.97 \\
\hline 30 & 24 & 0.8 & 130 & 250 & 6.0 & 16.30 & 3.78 & 535 & 0.83 \\
\hline
\end{tabular}




\begin{tabular}{|l|l|l|l|l|l|l|l|l|l|}
\hline 35 & 28 & 0.8 & 130 & 250 & 6.0 & 18.13 & 4.27 & 655 & 0.85 \\
\hline 40 & 32 & 0.8 & 130 & 250 & 6.0 & 19.80 & 5.01 & 820 & 0.87 \\
\hline 20 & 20 & 1.0 & 130 & 250 & 6.0 & 11.76 & 2.30 & 235 & 0.74 \\
\hline 25 & 25 & 1.0 & 130 & 250 & 6.0 & 13.89 & 2.67 & 320 & 0.77 \\
\hline 30 & 30 & 1.0 & 130 & 250 & 6.0 & 15.79 & 2.85 & 365 & 0.79 \\
\hline 35 & 35 & 1.0 & 130 & 250 & 6.0 & 17.50 & 3.65 & 545 & 0.83 \\
\hline 10 & 6 & 0.6 & 150 & 160 & 6.0 & 6.02 & 3.47 & 405 & 0.79 \\
\hline 15 & 9 & 0.6 & 150 & 160 & 6.0 & 8.62 & 4.37 & 575 & 0.83 \\
\hline 20 & 12 & 0.6 & 150 & 160 & 6.0 & 10.99 & 4.91 & 690 & 0.85 \\
\hline 25 & 15 & 0.6 & 150 & 160 & 6.0 & 13.16 & 5.56 & 835 & 0.87 \\
\hline 30 & 18 & 0.6 & 150 & 160 & 6.0 & 15.15 & 6.45 & 990 & 0.95 \\
\hline 35 & 21 & 0.6 & 150 & 160 & 6.0 & 16.99 & 7.70 & 950 & 0.97 \\
\hline 40 & 24 & 0.6 & 150 & 160 & 6.0 & 18.69 & 9.00 & 990 & 0.99 \\
\hline 10 & 8 & 0.8 & 150 & 160 & 6.0 & 5.95 & 2.69 & 280 & 0.75 \\
\hline 15 & 12 & 0.8 & 150 & 160 & 6.0 & 8.47 & 3.04 & 350 & 0.78 \\
\hline 20 & 16 & 0.8 & 150 & 160 & 6.0 & 10.75 & 3.62 & 470 & 0.81 \\
\hline 25 & 20 & 0.8 & 150 & 160 & 6.0 & 12.82 & 4.38 & 630 & 0.84 \\
\hline 30 & 27 & 0.8 & 150 & 160 & 6.0 & 14.71 & 5.51 & 875 & 0.88 \\
\hline 10 & 10 & 1.0 & 150 & 160 & 6.0 & 5.88 & 2.21 & 200 & 0.71 \\
\hline 15 & 15 & 1.0 & 150 & 160 & 6.0 & 8.33 & 2.59 & 280 & 0.75 \\
\hline 20 & 20 & 1.0 & 150 & 160 & 6.0 & 10.53 & 3.32 & 425 & 0.80 \\
\hline 25 & 25 & 1.0 & 150 & 160 & 6.0 & 12.50 & 4.32 & 635 & 0.85 \\
\hline 30 & 30 & 1.0 & 150 & 160 & 6.0 & 14.29 & 4.50 & 684 & 0.85 \\
\hline
\end{tabular}

\section{Conclusion}

In order to prevent serious industrial accidents caused by hydrogen, this study developed a hydrogen plasma treatment unit and constructed a hydrogen exhaust safety system. This idea provides a new solution to prevent serious industrial accidents caused explosion due to hydrogen leaks.

The results of three feasibility experiments have shown that a mixture of hydrogen and oxygen and plasma energy is converted into water vapor through decomposition and chemical reaction in the HPTU. The decomposition rate was inversely proportional to the amount of hydrogen and proportional to the amount of oxygen and RF power. We have succeeded in finding a new method for safe exhaust of hydrogen by methods other than nitrogen dilution. In addition, the risk of hydrogen explosion can be avoided by means of a hydrogen exhaust safety system.

The combination of HPTU and NDU allowed to decompose and dilute 40slm of hydrogen to control concentrations below the lower explosive limit of $1 \%$. There was a physical contradiction between safe hydrogen exhaust and overloading of gas scrubber, but it was solved by the principle of conditional separation. The core component of the hydrogen exhausr safety system is HPTU, anf the core technology is to control the NDU's diluted nitrogen input based on the exhaust concentration detected by the hydrogen sensor.

FOS technology one of TRIZ has proven useful when developing new devices and methods. A new system can be introduced with minimal trial and error, and uncertainty can be eliminated, so it can be quickly applied to the industry.

Hydrogen is converted into water vapor, a safe substance, and can be safely exhausted by nitrogen dilution, which is expected to help prevent serious industrial accidents. In addition, HPTU is expected to have great utility in other industries and sectors that use large amount of hydrogen. 
Since it was developed mainly for exhausting in the form of hydrogen in a vacuum region, there are limitations when it contains a lot of impurities or is not in a vacuum state. Thus, there is a need to continue the development devices that can be used in various cases of hydrogen exhaust.

\section{Acknowledgments}

This research was supported by Basic Science Research Program through the National Research Foundation of Korea (NRF) funded by the Ministry of Education (2018R1D1A1B07049244)

\section{References}

[1] Technical guidelines for the safety of hydrogen storage facilities, KOSHA CODE : D-23-2002, https://kosha.or.kr/kosha/data/guidanceDetail.do

[2] B. Sergey, Dorofeev, Flame Acceleration and Explosion Safety Applications, Proceedings of Combusition Institute, (2011), Vol.33, No.2, pp.2161-2175, https://doi.org/10.1016/j.proci.2010.09.008

[3] D. Bjerketvedt, J. R. Bakke, K. V. Wingerden, Gas explosion hand book, Journal of Hazardous Materials, (1997), Vol.52, No.1, pp.1-150, https://doi.org/10.1016/S0304-3894(97)81620-2

[4] Y. D. Jo, S. S. Tak, G. S. Choi, J. R. Lee, K. S. Park, Analysis of Hydrogen Accident in Korea, Transactions of the Korean Hydrogen and New Energy Society, (2004), Vol.15, No.1, pp.82-87, UCI : G704-001444.2004.15.1.004

[5] V. Schroeder, K. Holtappels, Explosion Characteristics of Hydrogen-air and hydrogen-oxygen mixtures at elevated pressure, Hydrogen tools, (2005)

[6] V. Schroeder, Explosionsgrenzen von Wasserstoffund Wasserstoff /Methan-Gemischen: BAM Research, Report No. 253, NW-Verlog, Bremerhaven, (2003)

[7] T. Jones, Explosive nature of Hydrogen in partial-pressure vacuum, The American Ceramic Society, (2009), Vol.9, No.1, pp.1-4

[8] V. Souchkov, A Brief History of TRIZ, The TRIZ Journal, (2015), pp.1-10.

[9] I. M. Ilevbare, D. Probert, R. Phaal, A Review of TRIZ and Its Benefits and Challenges in Practice, Technovation, (2013), Vol.33, No.2-3, pp.30-37, https://doi.org/10.1016/j.technovation.2012.11.003

[10] Y. W. Song, Analysis of Technology Evolution Trends for Predicting Future Technologies, Asia-pacific Journal of Convergent Research Interchange, (2020), Vol.6, No.10, pp.123-136.

[11] C. W. Park, M. E. Lee, S. T. Lee, Y. W. Song, Analysis of Technological Evolution for TV Displays Using S-Curves, Asia-pacific Journal of Convergent Research Interchange, (2020), Vol.6, No.10, pp.147-163.

[12] http//www.recarboninc.com/technology, (2017)

[13] S. M Seo, Development of HPS (Hydrogen Plasma-treatment System) using TRIZ, Journal of the Korea Management Engineers Society, (2020), Vol.25, No.2, pp.171-185, DOI : 10.35373/KMES.25.2.10

[14] S. M Seo, Development of Hydrogen Exhaust Safety System using TRIZ \& Design of Experiment, Graduate School of Myungji University, Doctoral Dissertation, (2020) 